\title{
Spectral-domain optical coherence tomography findings in polypoidal choroidal vasculopathy suggest a type I neovascular growth pattern
}

This article was published in the following Dove Press journal:

Clinical Ophthalmology

I September 2014

Number of times this article has been viewed

\author{
Saeed T Alshahrani ${ }^{1,2}$ \\ Hanan N Al Shamsi ${ }^{2}$ \\ Eman S Kahtani² \\ Nicola G Ghazi ${ }^{2,3}$ \\ 'King Fahad Specialist Hospital, \\ Dammam, Saudi Arabia; ${ }^{2}$ King Khaled \\ Eye Specialist Hospital, Riyadh, \\ Saudi Arabia; ${ }^{3}$ University of Virginia, \\ Department of Ophthalmology, \\ Charlottesville, VA, USA
}

Purpose: To report spectral-domain optical coherence tomography (SD-OCT) findings in polypoidal choroidal vasculopathy (PCV).

Patients and methods: Seventeen eyes of 15 consecutive patients diagnosed with PCV based on typical clinical and angiographic findings were imaged with macular SD-OCT including line scans passing through the polyps.

Results: SD-OCT findings included typical and atypical retinal pigment epithelial (RPE) detachments and subretinal and intraretinal fluid in all eyes. In the areas corresponding to the polypoidal lesions, well-delineated round-oval, sub-RPE cavities were present and were adherent to the posterior surface of the detached RPE above Bruch membrane. No retinal or choroidal connections to the cavities were noted.

Conclusion: These SD-OCT findings document that the vascular lesions in PCV are not located in the inner choroid, but in the sub-RPE space, suggesting that PCV is a variant of type 1 choroidal neovascularization rather than a distinct clinical entity as initially thought.

Keywords: choroidal neovascularization, retinal pigment epithelial detachments, vascular lesion, SD-OCT, type 1 choroidal neovascularization

\section{Introduction}

Polypoidal choroidal vasculopathy (PCV) was initially described as a distinct choroidal vascular abnormality characterized by recurrent subretinal pigment epithelial bleeding and serosanguineous complications in the posterior pole. ${ }^{1-4}$ Later on, the spectrum of the disease was expanded..$^{5-7}$ However, it remains controversial whether PCV is a true distinct entity or a variant of type 1 choroidal neovascularization (CNV), despite reportedly different clinical characteristics, natural course and response to treatment. ${ }^{4}$ Both entities usually show characteristics of an occult lesion on fluorescein angiography and indocyanine green angiography (ICGA) may show hyperfluorescent "hot spots" in both, although a cluster of subretinal hot spots is characteristic of PCV, especially when associated with a branching choroidal vascular network (BVN). ${ }^{8}$ Early timedomain optical coherence tomography (TD-OCT) studies showed that the polypoidal lesions as well as the BVN as seen on ICGA were associated with "atypical" pigment epithelial detachments (PEDs), and careful review of the illustrations suggests that these lesions may be located anterior to Bruch membrane. ${ }^{9,10}$ However, TD-OCT has a poor definition of the outer retinal layers, and while the findings are suggestive of a sub-retinal pigment epithelial (sub-RPE) location of PCV, they are not confirmatory. Spectral-domain optical coherence tomography (SD-OCT) has a superior ability to resolve the outer retinal layers and may offer an opportunity to better define the
Correspondence: Nicola G Ghazi, Division of Vitreoretinal Surgery, King Khaled Eye Specialist Hospital, PO Box 7I9I, Riyadh II462, Kingdom of Saudi Arabia Email nicola.ghazi@gmail.com 
location of PCV lesions in vivo. In this study, we examined patients with a typical presentation of PCV both clinically and angiographically, using SD-OCT in an effort to characterize the RPE and sub-RPE space in this disease and localize the PCV lesions seen on ICGA.

\section{Patients, materials and methods}

A case series of 17 eyes of 15 consecutive patients diagnosed with PCV was conducted following approval by the Institutional Review Board at the King Khaled Eye Specialist Hospital, Riyadh, Kingdom of Saudi Arabia. The diagnosis of PCV was based on typical clinical and angiographic findings, including ICGA. All ICGA studies were performed using a scanning laser ophthalmoscope (Heidelberg Retina Angiograph 2 [HRA2]; Heidelberg Engineering $\mathrm{GmbH}$, Heidelberg, Germany). Clinical criteria for the diagnosis of PCV included serous, serosanguineous, and hemorrhagic detachments of the retina, and RPE in the posterior pole or periphery in a relatively elderly patient; exudation, reddish-orange "inner choroidal" vascular abnormalities and nodules; general rarity of drusen; poor response to prior anti-vascular endothelial growth factor agents; an occult CNV picture on fluorescein angiography; and evidence of deep hyperfluorescent aneurismal dilatations on ICGA with or without a BVN. ${ }^{11,12}$ Two eyes were seen by remote consultation. Both were originally diagnosed with age-related macular degeneration (AMD), and one was treated with intravitreal anti-vascular endothelial growth factor injections. Only angiographic and SD-OCT data are available, but not detailed historical and follow-up data. Although we do not have detailed historical and follow-up data for these two eyes, we decided to include them in this series because we had enough angiographic and SD-OCT information to make the diagnosis and analyze the imaging findings for the purpose of this study.

Following a complete ophthalmic evaluation, all eyes were imaged with macular SD-OCT including line scans passing through the aneurismal dilatations noted on ICGA. Enhanced depth imaging was not performed. SD-OCT imaging was performed using a Spectralis unit ( Heidelberg Engineering $\mathrm{GmbH}$ ) in all cases. All eyes underwent a macular cube acquisition protocol with a scan pattern of $25^{\circ} \mathrm{C} \times 20^{\circ} \mathrm{C}$ consisting of a raster of 19 horizontal line-scans with a scanning density of 512 A-scans per line and an averaging parameter of 9 times (retinal thickness analysis [RTA] =9) while correcting for eye movements using the proprietary TruTrack function. In addition, single line scans passing through the aneurismal dilatations noted on ICGA were obtained with a scanning density of $768 \mathrm{~A}$-scans per line and an averaging parameter of 25 times $($ RTA $=25)$. All OCT scans were analyzed by one of us looking at the intraretinal, subretinal, and sub-RPE changes.

\section{Results}

The age of the patients ranged from 40 to 80 years (mean age, $68.23 \pm 11.02$ years), and the visual acuity of the involved eye ranged from $20 / 50$ to $1 / 200$ (reading the 20/200 optotype at 1 foot) (Table 1). Two patients had both eyes affected with PCV at presentation. Thirteen eyes were previously diagnosed with wet AMD; three eyes had other associated diagnoses including central serous choroidopathy, presumed intraocular tuberculosis, and reticular pattern dystrophy of the RPE; and the remaining eye was incorrectly thought to have choroidal melanoma. Fluorescein angiography disclosed features of occult without classic CNV in the form of stippled hyperfluorescence with minimal late leakage, or minimally classic CNV in 14 eyes, and predominantly classic CNV in three eyes. All eyes had typical polyps on angiography, and five had a clearly associated BVN on ICGA.

On SD-OCT cube imaging, all 17 eyes showed subretinal fluid (SRF) in association with PEDs. The extent of SRF and severity of PED was variable. Five of the 17 eyes had only SRF without intraretinal fluid, and the remaining 12 had both SRF and intraretinal fluid. SD-OCT line scans passing through the PCV lesions seen on ICGA showed remarkably unifying features in all eyes, in that all had a sub-RPE hyperreflective tissue similar to what is seen in type 1 (occult) $\mathrm{CNV}$. None of the eyes showed evidence of CNV in the subretinal space (type $2 \mathrm{CNV}$ ). All eyes had PEDs that were atypical in morphology and content. These PEDs assumed a corrugated or "bumpy" configuration (Figure 1). In some of the cases, the bumps of the RPE line were markedly abrupt, yielding an "M-shaped" or even a "QRS complex-shaped" PED (Figure 2) on some of the OCT line scans. In addition, careful assessment of the contents of these atypical PEDs disclosed well-delineated, round-oval, sub-RPE cavities with low to medium reflectivity centrally, and hyper-reflective borders resembling vascular cavities. These structures were always adherent to the posterior surface of the elevated RPE line, which appeared to be draped over them, and corresponded to the polyps seen on ICGA (Figures 1-5). In the eyes with a clearly defined, associated BVN seen on ICGA, the SD-OCT line scans of the corresponding area disclosed a moderately hyper-reflective tissue underneath the elevated RPE (Figure 4). We speculate that this moderately hyper-reflective tissue and the round-oval, sub-RPE cavities 
Table I Patient characteristics and disease course*

\begin{tabular}{|c|c|c|c|c|c|c|c|c|}
\hline $\begin{array}{l}\text { Case } \\
\text { no }\end{array}$ & Age & Sex & $\begin{array}{l}\text { Involved } \\
\text { eye }\end{array}$ & $\begin{array}{l}\text { VA at } \\
\text { presentation** }\end{array}$ & $\begin{array}{l}\text { VA at last } \\
\text { follow-up** }\end{array}$ & $\begin{array}{l}\text { Associated } \\
\text { diagnoses }\end{array}$ & $\begin{array}{l}\text { Treatment prior to } \\
\text { referral } \times \text { number } \\
\text { of treatments }\end{array}$ & $\begin{array}{l}\text { Treatment after } \\
\text { diagnosis } \times \text { number } \\
\text { of treatments }\end{array}$ \\
\hline I & 76 & $M$ & OD & $20 / 125$ & $2 / 200$ & AMD & Avastin $\times 7$ & $\begin{array}{l}\text { PDT } \times 1 \\
\text { Avastin } \times 1\end{array}$ \\
\hline \multirow[t]{2}{*}{2} & 74 & $\mathrm{~F}$ & OD & $20 / 200$ & $20 / 400$ & $\begin{array}{l}\text { Presumed } \\
\text { intraocular TB }\end{array}$ & Systemic anti-TB & Focal laser $\times 3$ \\
\hline & & & OS & $20 / 125$ & $20 / 300$ & AMD & None & $\begin{array}{l}\text { Focal laser } \times 1 \\
\text { Avastin } \times 3\end{array}$ \\
\hline 3 & 55 & $M$ & OD & $3 / 200$ & $20 / 400$ & AMD & Avastin $\times 2$ & $\begin{array}{l}\text { PDT } \times 3 \\
\text { Avastin } \times 9 \\
\text { Lucentis } \times 1\end{array}$ \\
\hline 4 & 75 & M & OS & $\mathrm{I} / 200$ & $20 / 400$ & AMD & Avastin $\times 3$ & $\begin{array}{l}\text { PDT } \times I \\
\text { Avastin } \times I\end{array}$ \\
\hline 5 & 40 & M & OS & $20 / 50$ & $20 / 30$ & AMD & Avastin $\times 3$ & Avastin $\times 4$ \\
\hline 6 & 73 & M & OD & $20 / 50$ & $20 / 40$ & $\begin{array}{l}\text { Choroidal } \\
\text { melanoma }\end{array}$ & None & $\begin{array}{l}\text { PPV for vitreous } \\
\text { hemorrhage }+ \text { focal laser }\end{array}$ \\
\hline 7 & 61 & M & OD & $20 / 50$ & $20 / 30$ & CSC & Avastin $\times 4$ & $\begin{array}{l}\text { PDT } \times 3 \\
\text { Avastin } \times 1 \\
\text { Kenalog } \times 3 \\
\text { Lucentis } \times 7\end{array}$ \\
\hline 8 & 66 & M & OD & $20 / 100$ & $20 / 80$ & AMD & None & $\begin{array}{l}\text { PDT } \times 1 \\
\text { Avastin } \times 6 \\
\text { Decadron } \times 1 \\
\text { Lucentis } \times 1\end{array}$ \\
\hline 9 & 67 & M & OD & $20 / 100$ & $20 / 60$ & AMD & None & None \\
\hline 10 & 79 & $\mathrm{~F}$ & OD & $20 / 400$ & $20 / 200$ & AMD & None & $\begin{array}{l}\text { PDT } \times 1 \\
\text { Avastin } \times 2\end{array}$ \\
\hline & & & OS & $20 / 50$ & $20 / 40$ & & None & $\begin{array}{l}\text { PDT } \times 1 \\
\text { Avastin } \times 1\end{array}$ \\
\hline II & 71 & M & OD & $20 / 80$ & $20 / 70$ & AMD & None & $\begin{array}{l}\text { PDT } \times 1 \\
\text { Avastin } \times 1\end{array}$ \\
\hline 12 & 80 & M & OD & $20 / 70$ & $20 / 70$ & AMD & None & Focal laser \\
\hline 13 & 70 & $\mathrm{~F}$ & OD & $20 / 50$ & $20 / 125$ & $\begin{array}{l}\text { Reticular pattern } \\
\text { dystrophy of the } \\
\text { RPE }\end{array}$ & Avastin $\times I$ & $\begin{array}{l}\text { PDT } \times 1 \\
\text { Avastin } \times 11 \\
\text { Lucentis } \times 1\end{array}$ \\
\hline
\end{tabular}

Notes: *Two eyes were seen by remote consultation. Both were originally diagnosed with AMD and one was treated with intravitreal anti-vascular endothelial growth factor injections. Only angiographic and spectral-domain OCT data are available but not detailed historical and follow-up data. So, they were not included in the table even though they were included in the series analysis. **VA readings presented as I/200, 2/200, and 3/200 mean readings of the 200E optotype taken at I, 2 , and 3 feet, respectively. Abbreviations: no, number; VA, visual acuity; M, male; F, female; AMD, age-related macular degeneration; PDT, photodynamic therapy; OD, right eye; OS, left eye; TB, tuberculosis; CSC, central serous choroidopathy; RPE, retinal pigment epithelium; OCT, optical coherence tomography; PPV, pars plana vitrectomy.

represent the BVN and the polyps, respectively. In addition, both the polyps and the BVN were located anterior to Bruch membrane.

\section{Discussion}

These SD-OCT findings demonstrate that the vascular lesions seen on ICGA in PCV are not located in the inner choroid, as initially suggested, ${ }^{1,3,13}$ but rather in the sub-RPE space within an atypical PED and anterior to Bruch membrane. These findings are almost identical to those of Khan et $\mathrm{al}^{14}$ who reported 18 such cases with SD-OCT localization of the PCV lesions to the sub-RPE space. In addition, several other studies have suggested similar localization of the PCV lesions. ${ }^{4,9,10,15-18}$ This anatomical location is similar to that of type $1 \mathrm{CNV} \cdot{ }^{16,17,19-22}$ This, in turn, supports the notion that $\mathrm{PCV}$ is a variant of type $1 \mathrm{CNV}$ and is further evidence that PCV is a neovascular growth pattern, rather than a distinct clinical entity of the native inner choroidal vessels. Our study demonstrates that the two main SD-OCT distinguishing features of PCV lesions are: 1) the polyps seen in the sub-RPE space adherent to the posterior surface of the RPE; and 2) the atypical bumpy PEDs that can be M-shaped or even QRS complex-shaped, as illustrated in this study. In our experience, the combination of these two features is pathognomonic of PCV. These SD-OCT findings may be of value in at least strongly suspecting the diagnosis in the absence of ICGA, 


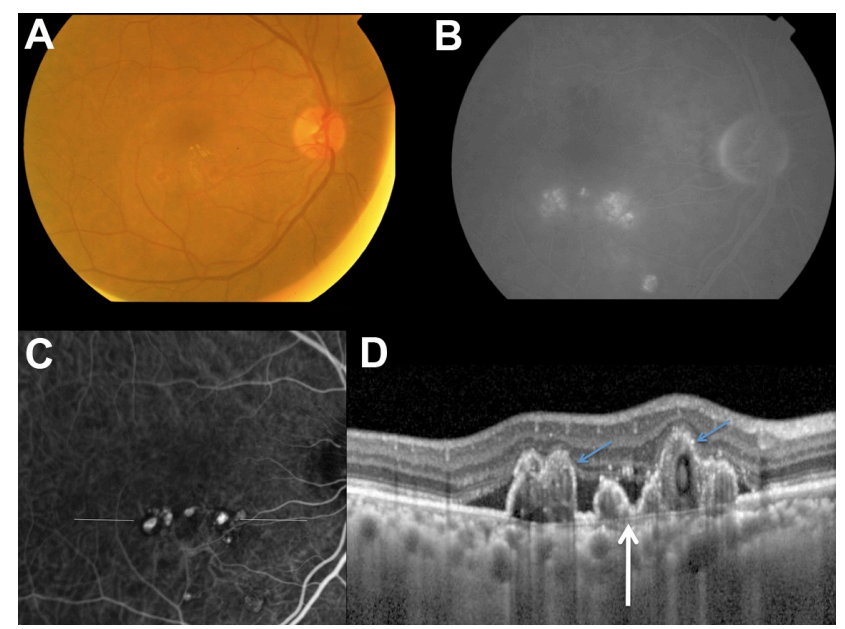

Figure I The right eye of a 66-year-old male (case 8) with polypoidal choroidal vasculopathy, initially diagnosed with age-related macular degeneration.

Notes: (A) Color fundus photograph showing subretinal fluid with hard exudates and orange-red nodules in the macula affecting the center of the fovea. (B) Late phase fluorescein angiography frame showing extrafoveal stippled hyperfluorescence with minimal leakage suggestive of an occult choroidal neovascular membrane. (C) Indocyanine green angiography revealing a well-defined branching vascular network with polypoidal terminations outside the foveal area. (D) Spectral-domain optical coherence tomography cross-sectional scan corresponding to the interrupted white line in (C). Note the atypical "bumpy" and "M-shaped" pigment epithelial detachment with well-delineated, round-oval, sub-RPE cavities (blue arrows) corresponding to the polyps in (C). The polyps are adherent to the posterior surface of the elevated RPE line and are anterior to Bruch membrane (white arrow). Abbreviation: RPE, retinal pigment epithelial.

which is not as widely utilized as fluorescein angiography. This, in turn, may prove helpful in treatment modification, particularly in cases resistant to conventional therapy with anti-vascular endothelial growth factor agents.

The suggestion that $\mathrm{PCV}$ is a neovascular process and a variant of type $1 \mathrm{CNV}$, rather than a distinct clinical entity, is also supported by clinical and histological findings. Clinical data suggest that PCV may complicate several maculopathies predisposing to CNV, particularly AMD. Most of the cases described in Caucasians to date, and many non-Caucasian cases, have been previously known to have AMD. ${ }^{14,23,24}$ Also, drusen are noted in many cases of PCV, and most cases have an occult presentation on fluorescein angiography. ${ }^{4,8}$ In addition, most patients with the disease are older than 50 years, and many have associated hypertension, similar to AMD. ${ }^{25}$ Finally, both inflammatory markers and genetic risk alleles associated with AMD have also been reported to be associated with PCV. ${ }^{26-28}$

Histological data from both submacular membranectomy specimens ${ }^{28-32}$ and enucleation specimens ${ }^{33-35}$ strongly support the sub-RPE location of the PCV lesions, and their similarities to type $1 \mathrm{CNV}$. Several submacular membranectomy studies reported the presence of large dilated blood vessels subjacent to the RPE and in close proximity to a layer of

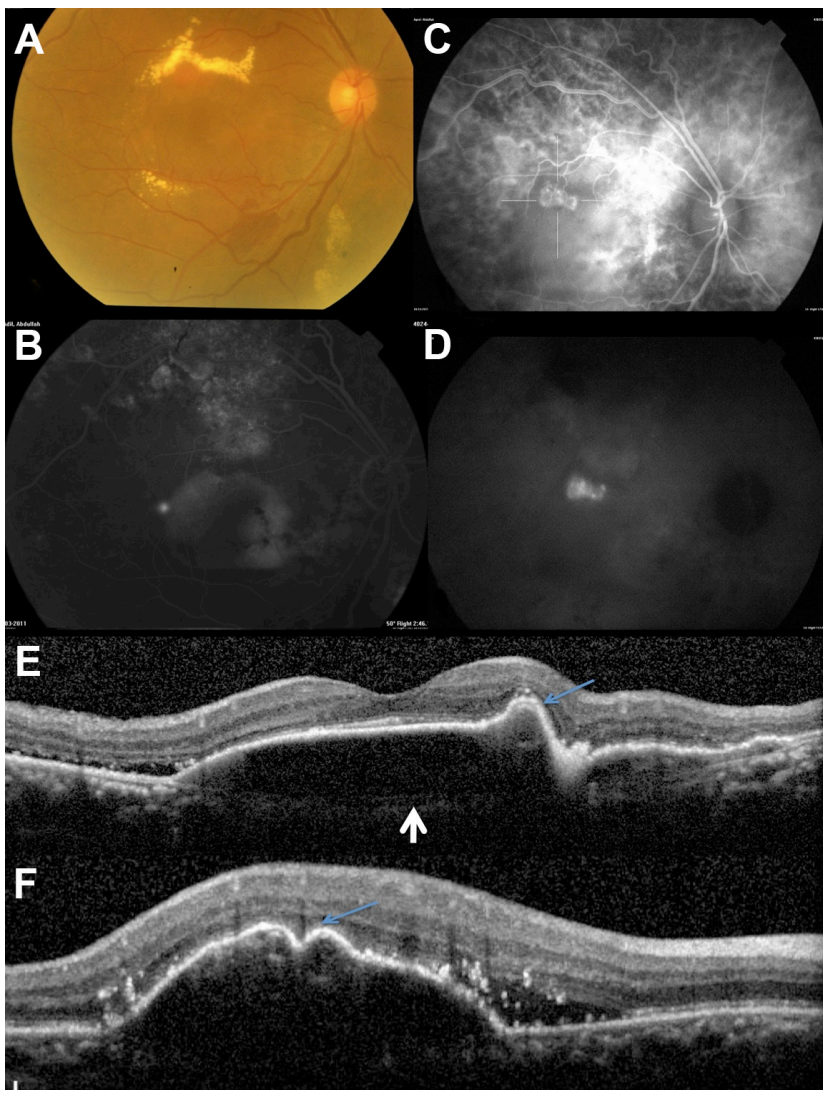

Figure 2 The right eye of a 75-year-old male (case 7) with polypoidal choroidal vasculopathy initially diagnosed with central serous choroidopathy.

Notes: (A) Color fundus photograph showing subretinal fluid with hard exudates, hemorrhage, orange-red nodules just inferior to the exudates, and a pigment epithelial detachment (PED) in the macula. (B) Fluorescein angiogram confirming the serosanguineous PED that is notched. Note the "ink-blot" leakage at the temporal edge of the PED and the irregular fluorescence superiorly. (C) and (D) Indocyanine green angiography revealing a fine branching vascular network with small polypoidal dilatations along the superior border of the PED. (E) and (F) Vertical and horizontal spectral-domain optical coherence tomography cross-sectional scans corresponding to the interrupted white lines in (C). Note the atypical "QRS complex-shaped" (E) and "M-shaped" (F) PEDs with well-delineated, round-oval, sub-RPE cavities (blue arrows) corresponding to the polyps in (C). The polyps are adherent to the posterior surface of the elevated RPE line and are anterior to Bruch membrane (white arrow).

Abbreviation: RPE, retinal pigment epithelial.

diffuse drusen and degenerated RPE, in an almost identical fashion to our SD-OCT findings. ${ }^{29-32}$ The main histological difference between the two entities is in relation to the size of the neovessels in the sub-RPE space in that PCV is characterized by atypically large blood vessels with unusual dilatations, unlike type $1 \mathrm{CNV}$, which is characterized by a fine network of predominantly capillary-sized vessels in the early stages, which may evolve into arteries and veins with time. ${ }^{19,20,29-37}$ Data from enucleation studies ${ }^{33-35}$ of eyes with presumed PCV have been less conclusive, largely because of the advanced nature of the disease process at the time of enucleation whereby all of them were either associated with end-stage hemorrhagic, or disciform processes. In two 


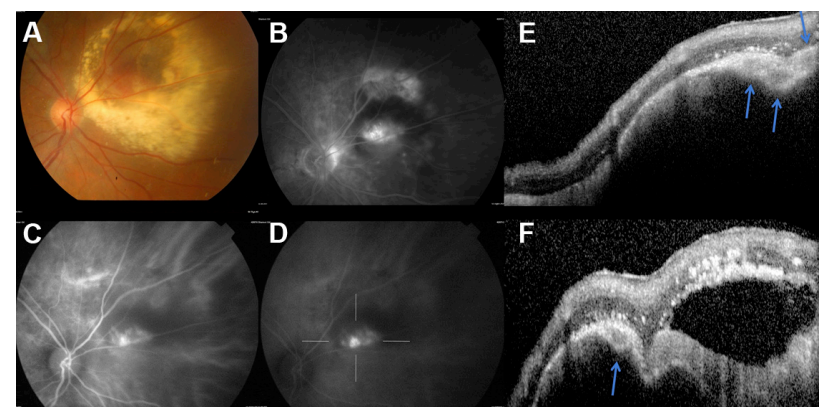

Figure 3 The right eye of a 73-year-old male (case 6) with polypoidal choroidal vasculopathy, who was diagnosed with choroidal melanoma.

Notes: (A) Color fundus photograph showing subretinal hemorrhage with extensive hard exudates, and orange-red nodules superonasal to the optic nerve head. (B) Fluorescein angiogram showing stippled hyperfluorescence, blockage from blood, and minimal leakage, suggestive of an occult choroidal neovascular membrane. (C) and (D) Indocyanine green angiography revealing a fine branching vascular network with small polypoidal dilatations. (E) and (F) Horizontal and vertical spectraldomain optical coherence tomography cross-sectional scans corresponding to the interrupted white lines in (D). Note the atypical "M-shaped" PED with welldelineated, round-oval, sub-RPE cavities (blue arrows) corresponding to the polyps in (D). The polyps are adherent to the posterior surface of the elevated RPE line.

Abbreviations: PED, pigment epithelial detachment; RPE, retinal pigment epithelial.

specimens, no polypoidal lesions could be demonstrated, but only sub-RPE and/or subretinal fibrovascular proliferation traversing breaks in Bruch membrane similar to those seen in typical macular degeneration could be seen. ${ }^{34,35}$ In a third

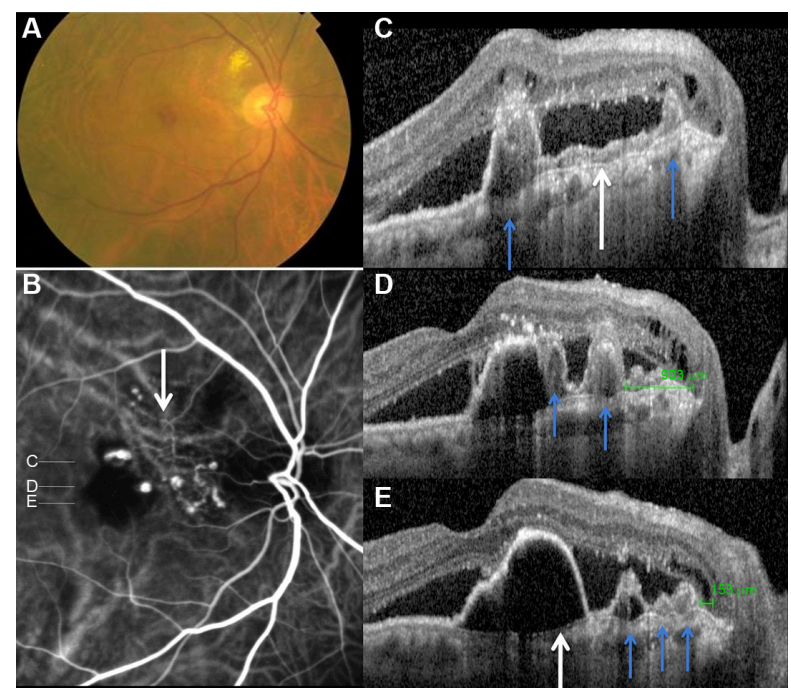

Figure 4 The right eye of a 7I-year-old male (case II) with bilateral idiopathic choroidal folds and polypoidal choroidal vasculopathy initially diagnosed with agerelated macular degeneration.

Notes: (A) Color fundus photograph showing subretinal fluid and hemorrhage in the fovea and peripapillary hard exudates. (B) Indocyanine green angiography revealing a branching vascular network (BVN) with small multiple polypoidal dilatations. (C-E) Horizontal spectral-domain optical coherence tomography cross-sectional scans corresponding to the labeled white lines in (B). Note the atypical corrugated, bumpy, and "M-shaped" PEDs with well-delineated, round-oval, sub-RPE cavities (blue arrows) corresponding to the polyps in (B). The polyps are adherent to the posterior surface of the elevated RPE line. Also note that the area of the BVN in (B) (white arrow), corresponds to a moderately hyper-reflective tissue in (C) sandwiched between the elevated RPE line and Bruch membrane (white arrow in [C]). Both the polyps and the BVN are located anterior to Bruch membrane (C-E).

Abbreviations: PED, pigment epithelial detachment; RPE, retinal pigment epithelial.

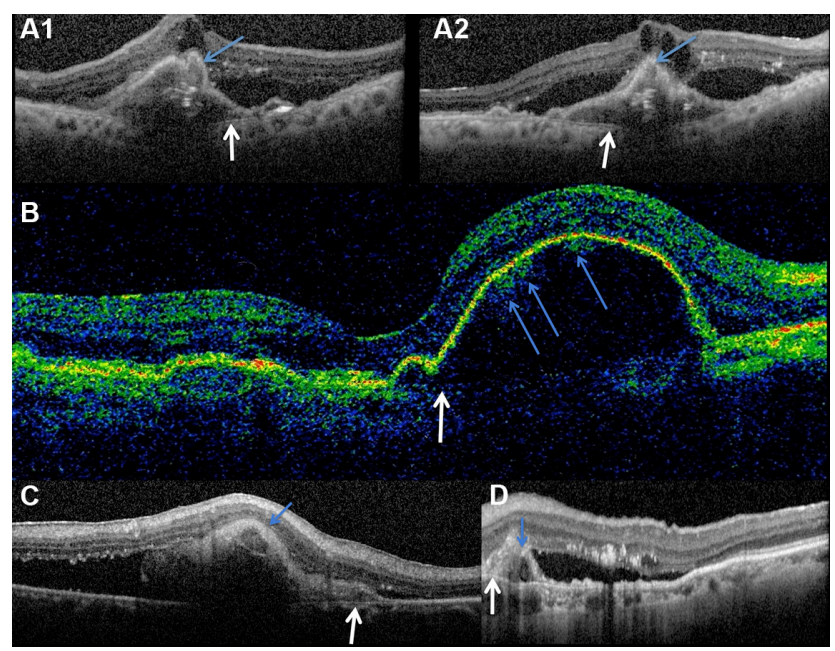

Figure 5 Four other eyes with spectral-domain optical coherence tomography showing atypical pigment epithelial detachments (PEDs) with polyps (blue arrows) adherent to the posterior surface of the elevated RPE line and anterior to Bruch membrane (white arrows).

Notes: (AI) and (A2) are vertical and horizontal line scans passing through a polypoidal lesion of the same eye, respectively. (B-D) are line scans passing through polypoidal lesions of three other eyes. Note the varying patterns of an "M-shaped" PED in (AI), (B), and (C).

Abbreviation: RPE, retinal pigment epithelial.

specimen, large dilated and thin-walled vessels were noted in the sub-RPE space/intra-Bruch region and were thought to originate from the ciliary vessels. ${ }^{33}$ Even though the latter (third) enucleation specimen is more convincing than the former two, the associated massive hemorrhagic and disciform complications, as well as the focal bone formation, suggest chronicity and advanced disease, making the findings less definitive. However, the authors conclude that PCV may be a form of AMD due to the sub-RPE/intra-Bruch location of the neovessels.

Some of the reasons that led to the suggestion that PCV is a distinct entity from AMD included the clinical presentation predominantly in the peripapillary area with a unique ICGA appearance, its ethnic predilection, the relatively favorable natural history, and its different response to therapy. ${ }^{4,5,7}$ However, all these are not sufficient reasons to make PCV a distinct entity. CNV in AMD may also be peripapillary in location. In addition, subsequent studies on PCV have demonstrated that the disease affects the macular area much more frequently than originally thought. ${ }^{4,538}$ The relatively favorable natural history of $\mathrm{PCV}^{39}$ and its different response to therapy ${ }^{40-42}$ also do not negate the hypothesis that PCV is a variant of type $1 \mathrm{CNV}$. For example, type $1 \mathrm{CNV}$ is also known to have a more favorable natural history than type 2 (classic) $\mathrm{CNV}^{43,44}$ as well as a different response to some forms of therapy, ${ }^{45-47}$ yet both can be variants of the same disease, such as neovascular AMD. In other words, having a different natural history 
and response to therapy does not necessarily make PCV a distinct entity. Moreover, the relatively better natural history of PCV may be at least in part directly related to its sub-RPE location and to it being a variant of type $1 \mathrm{CNV}$. The ethnic predilection of PCV remains unexplained.

In conclusion, these SD-OCT findings localize the vascular lesions in PCV to the sub-RPE space and strongly suggest that PCV is a variant of type $1 \mathrm{CNV}$. They also constitute strong complementary evidence to the available clinical and histological data supporting the hypothesis that PCV is not a distinct clinical entity but rather a neovascular process, which can complicate several entities, predominantly AMD, but also central serous choroidopathy, angioid streaks, myopia, and others. Therefore, we suggest the descriptive term "polypoidal PED" to describe the characteristic clinical presentation previously termed PCV and to categorize it as a third type of PED associated with type $1 \mathrm{CNV}$, in addition to serous and fibrovascular PED.

\section{Disclosure}

The authors report no conflicts of interest in this work.

\section{References}

1. Yannuzzi LA. Idiopathic polypoidal choroidal vasculopathy. Macula Society Meeting; 1982; Miami, FL.

2. Ciardella AP, Donsoff IM, Huang SJ, Costa DL, Yannuzzi LA. Polypoidal choroidal vasculopathy. Surv Ophthalmol. 2004;49(1):25-37.

3. Kleiner RC, Brucker AJ, Johnston RL. The posterior uveal bleeding syndrome. Retina. 1990;10(1):9-17.

4. Imamura Y, Engelbert M, Iida T, Freund KB, Yannuzzi LA. Polypoidal choroidal vasculopathy: a review. Surv Ophthalmol. 2010;55(6): 501-515.

5. Yannuzzi LA, Ciardella A, Spaide RF, Rabb M, Freund KB, Orlock DA. The expanding clinical spectrum of idiopathic polypoidal choroidal vasculopathy. Arch Ophthalmol. 1997;115(4):478-485.

6. Yannuzzi LA, Nogueira FB, Spaide RF, et al. Idiopathic polypoidal choroidal vasculopathy: a peripheral lesion. Arch Ophthalmol. 1998;116(3): 382-383.

7. Yannuzzi LA, Wong DWK, Sforzolini BS, et al. Polypoidal choroidal vasculopathy and neovascular age-related macular degeneration. Arch Ophthalmol. 1999;117(11):1503-1510.

8. Koh AH, Chen LJ, Chen SJ, Giridhar A, Iida T, Kim H, et al; Expert PCV Panel. Polypoidal choroidal vasculopathy: evidence-based guidelines for clinical diagnosis and treatment. Retina. 2013;33(4):686-716.

9. Iijima H, Iida T, Imai M, Gohdo T, Tsukahara S. Optical coherence tomography of orange-red subretinal lesions in eyes with idiopathic polypoidal choroidal vasculopathy. Am J Ophthalmol. 2000; 129(1):21-26.

10. Sato T, Kishi S, Watanabe G, Matsumoto H, Mukai R. Tomographic features of branching vascular networks in polypoidal choroidal vasculopathy. Retina. 2007;27(5):589-594.

11. Japanese Study Group of Polypoidal Choroidal Vasculopathy. [Criteria for diagnosis of polypoidal choroidal vasculopathy]. Nippon Ganka Gakkai Zasshi. 2005;109(7):417-427. Japanese [with English abstract].

12. Okubo A, Hirakawa M, Ito M, Sameshima M, Sakamoto T. Clinical features of early and late stage polypoidal choroidal vasculopathy characterized by lesion size and disease duration. Graefes Arch Clin Exp Ophthalmol. 2008;246(4):491-499.
13. Yannuzzi LA, Sorenson J, Spaide RF, Lipson B. Idiopathic polypoidal choroidal vasculopathy (IPCV). Retina. 1990;10(1):1-8.

14. Khan S, Engelbert M, Imamura Y, Freund KB. Polypoidal choroidal vasculopathy: simultaneous indocyanine green angiography and eyetracked spectral domain optical coherence tomography findings. Retina. 2012;32(6):1057-1068.

15. Saito M, Iida T, Nagayama D. Cross-sectional and en face optical coherence tomographic features of polypoidal choroidal vasculopathy. Retina. 2008;28(3):459-464.

16. Miura M, Makita S, Iwasaki T, Yasuno Y. Three-dimensional visualization of ocular vascular pathology by optical coherence angiography in vivo. Invest Ophthalmol Vis Sci. 2011;52(2):2689-2695.

17. Yasuno Y, Miura M, Kawana K, et al. Visualization of sub-retinal pigment epithelium morphologies of exudative macular diseases by high-penetration optical coherence tomography. Invest Ophthalmol Vis Sci. 2009;50(1):405-413.

18. Kameda T, Tsujikawa A, Otani A, et al. Polypoidal choroidal vasculopathy examined with en face optical coherence tomography. Clin Experiment Ophthalmol. 2007;35(7):596-601.

19. Bressler SB, Silva JC, Bressler NM, Alexander J, Green WR. Clinicopathologic correlation of occult choroidal neovascularization in age-related macular degeneration. Arch Ophthalmol. 1992;110(6):827-832.

20. Green WR. Histopathology of age-related macular degeneration. Mol Vis. 1999;5:27.

21. Liakopoulos S, Ongchin S, Bansal A, et al. Quantitative optical coherence tomography findings in various subtypes of neovascular agerelated macular degeneration. Invest Ophthalmol Vis Sci. 2008;49(11): 5048-5054.

22. Coscas F, Coscas G, Souied E, Tick S, Soubrane G. Optical coherence tomography identification of occult choroidal neovascularization in age-related macular degeneration. Am J Ophthalmol. 2007;144(4): 592-599.

23. Freund KB, Zweifel SA, Englebert M. Do we need a new classification for choroidal neovascularization in age-related macular degeneration? Retina. 2010;30(9):1333-1349.

24. Tsujikawa A, Ojima Y, Uamashiro K, et al. Development of polypoidal lesions in age-related macular degeneration. Eye (Lond). 2011;25(4): 481-488.

25. Perkovich BT, Zakov ZN, Berlin LA, Weidenthal D, Avins LR. An update on multiple recurrent serosanguineous retinal pigment epithelial detachments in black women. Retina. 1990;10(1):18-26.

26. Cheng Y, Huang L, Li X, Zhou P, Zeng W, Zhang C. Genetic and functional dissection of ARMS2 in age-related macular degeneration and polypoidal choroidal vasculopathy. PLoS One. 2013;8(1):e53665.

27. Jiang JJ, Wu X, Zhou P, Yu WZ, Huang LZ, Li XX. Meta-analysis of the relationship between the LOC387715/ARMS2 polymorphism and polypoidal choroidal vasculopathy. Genet Mol Res. 2012;11(4): 4256-4267.

28. Lima LH, Schubert C, Ferrara DC, et al. Three major loci involved in age-related macular degeneration are also associated with polypoidal choroidal vasculopathy. Ophthalmology. 2010;117(8):1567-1570.

29. Lafaut BA, Aisenbrey S, Van den Broecke C, Bartz-Schmidt KU, Heimann K. Polypoidal choroidal vasculopathy pattern in age-related macular degeneration: a clinicopathologic correlation. Retina. 2000; 20(6):650-654.

30. Okubo A, Sameshima M, Uemura A, Kanda S, Ohba N. Clinicopathological correlation of polypoidal choroidal vasculopathy revealed by ultrastructural study. Br J Ophthalmol. 2002;86(10):1093-1098.

31. Nakajima M, Yuzawa M, Shimada H, Mori R. Correlation between indocyanine green angiographic findings and histopathology of polypoidal choroidal vasculopathy. Jpn J Ophthalmol. 2004;48(3):249-255.

32. Nakashizuka H, Mitsumata M, Okisaka S, et al. Clinicopathologic findings in polypoidal choroidal vasculopathy. Invest Ophthalmol Vis Sci. 2008;49(11):4729-4737.

33. Rosa RH Jr, Davis JL, Eifrig CW. Clinicopathologic reports, case reports, and small case series: clinicopathologic correlation of idiopathic polypoidal choroidal vasculopathy. Arch Ophthalmol. 2002;120(4): 502-508. 
34. MacCumber MW, Dastgheib K, Bressler NM, et al. Clinicopathologic correlation of the multiple recurrent serosanguineous retinal pigment epithelial detachments syndrome. Retina. 1994;14(2):143-152.

35. Spraul CW, Grossniklaus HE, Lang GK. [Idiopathic polypoidal choroidal vasculopathy.] Klin Monatsbl Augenheilkd. 1997;210(6):405-406. German.

36. Klein ML, Wilson DJ. Clinicopathologic correlation of choroidal and retinal neovascular lesions in age-related macular degeneration. Am J Ophthalmol. 2011;151(1):161-169.

37. Green WR, Enger C. Age-related macular degeneration histopathologic studies. The 1992 Lorenz E Zimmerman Lecture. Ophthalmology. 1993; 100(10):1519-1535.

38. Scassellati-Sforzolini B, Mariotti C, Bryan R, Yannuzzi LA, Giuliani M, Giovannini A. Polypoidal choroidal vasculopathy in Italy. Retina. 2001;21(2):121-125.

39. Uyama M, Wada M, Nagai Y, et al. Polypoidal choroidal vasculopathy: natural history. Am J Ophthalmol. 2002;133(5):639-648.

40. Koh A, Lee WK, Chen LJ, et al. EVEREST study: efficacy and safety of verteporfin photodynamic therapy in combination with ranibizumab or alone versus ranibizumab monotherapy in patients with symptomatic macular polypoidal choroidal vasculopathy. Retina. 2012;32(8): 1453-1464.

41. Mitamura Y, Kitahashi M, Kubota-Taniai M, Yamamoto S. Comparison of intravitreal bevacizumab to photodynamic therapy for polypoidal choroidal vasculopathy: short-term results. Indian J Ophthalmol. 2010; 58(4):291-296.
42. Spaide RF, Donsoff I, Lam DL, et al. Treatment of polypoidal choroidal vasculopathy with photodynamic therapy. Retina. 2002; 22(5):529-535.

43. Stevens TS, Bressler NM, Maguire MG, et al. Occult choroidal neovascularization in age-related macular degeneration. A natural history study. Arch Ophthalmol. 1997;115(3):345-350.

44. Pieramici DJ, Bressler SB, Koester JM, Bressler NM. Occult with no classic subfoveal choroidal neovascular lesions in age-related macular degeneration: clinically relevant natural history information in larger lesions with good vision from the Verteporfin in Photodynamic Therapy (VIP) Trial: VIP Report No 4. Arch Ophthalmol. 2006;124(5):660-664.

45. Bressler NM; Treatment of Age-Related Macular Degeneration with Photodynamic Therapy (TAP) Study Group. Photodynamic therapy of subfoveal choroidal neovascularization in age-related macular degeneration with verteporfin: two-year results of 2 randomized clinical trials-tap report 2. Arch Ophthalmol. 2001;119(2):198-207.

46. Verteporfin In Photodynamic Therapy Study Group. Verteporfin therapy of subfoveal choroidal neovascularization in age-related macular degeneration: two-year results of a randomized clinical trial including lesions with occult with no classic choroidal neovascularization verteporfin in photodynamic therapy report 2. Am J Ophthalmol. 2001; 131(5):541-560.

47. Macular Photocoagulation Study Group. Occult choroidal neovascularization. Influence on visual outcome in patients with age-related macular degeneration. Arch Ophthalmol. 1996;114(4):400-412.
Clinical Ophthalmology

\section{Publish your work in this journal}

Clinical Ophthalmology is an international, peer-reviewed journa covering all subspecialties within ophthalmology. Key topics include: Optometry; Visual science; Pharmacology and drug therapy in eye diseases; Basic Sciences; Primary and Secondary eye care; Patien Safety and Quality of Care Improvements. This journal is indexed on

Submit your manuscript here: http://www.dovepress.com/clinical-ophthalmology-journal

\section{Dovepress}

PubMed Central and CAS, and is the official journal of The Society of Clinical Ophthalmology (SCO). The manuscript management system is completely online and includes a very quick and fair peer-review system, which is all easy to use. Visit http://www.dovepress.com/ testimonials.php to read real quotes from published authors. 